\title{
17. Mutagenic Principle(s) in Tryptophan and Phenylalanine Pyrolysis Products
}

\author{
By Takashi Sugimura, *) Takashi KaWACHI,*) Minako Nagao,*) \\ Takie YaHAGI, *) Yuko SEINo,*) Toshihiko OKamoto,**) \\ Koichi Shudo,**) Takuo Kosuge,***) Kuniro TsuJI,***) \\ Keiji WAKABAYASHI,***) Yoichi IITAKA,**) \\ and Akiko ITAI**) \\ (Communicated by Hamao UmezAwA, M. J. A., Jan. 12, 1977)
}

We previously reported that smoke condensates from fish showed high mutagenic activity (Nagao et al., 1977a; Sugimura et al., 1977). Charred material in the surface layer of broiled fish and meat also contained a high mutagenic potential (Nagao et al., 1977a; Sugimura et al., 1977). Subsequently it was revealed that mutagenic principles were formed by pyrolysis of protein but not carbohydrate, nucleic acid and vegetable oil (Sugimura et al., 1977). This report deals with mutagenic principles in the pyrolysis products of $\mathrm{D}$, L-tryptophan and D, L-phenylalanine. The most plausible structures from the former were 3-amino-1, 4-dimethyl-5H-pyrido[4,3-b]indole and 3amino-1-methyl-5H-pyrido $[4,3-b]$ indole. The structure of the active principle of $\mathrm{D}$, L-phenylalanine was proved to be 2-amino-5-phenylpyridine.

Since pyrolysis products are very likely to be produced by cooking proteinous food, such as fish and meat, by direct exposure to the flame, and since the correlation between mutagens and carcinogens have been generally accepted in recent investigations (McCann et al., 1975 ; Sugimura et al., 1976), there is a strong probability that cooked foods in which charred material from proteinous components are produced might play a role in carcinogenesis generally occurring in human.

Mutagenicity tests were carried out using an improved method (Nagao et al., 1977b; Yahagi et al., 1977) of the Ames test (Ames et al., 1975). Test material, bacteria and S-9 Mix prepared from the liver of rats treated with polychlorinated biphenyl were prein\footnotetext{
Tokyo 104.

**) Faculty of Pharmaceutical Science, University of Tokyo, 7-3-1, Hongo, Bunkyo-ku, Tokyo 113.

***) Shizuoka College of Pharmacy, 2-2-1, Oshika, Shizuoka-shi, Shizuokaken 422.
}

*) National Cancer Center Research Institute, 5-1-1, Tsukiji, Chuo-ku, 
cubated at $37^{\circ} \mathrm{C}$ for $20 \mathrm{~min}$. TA98 strain of Salmonella typhimurium was kindly supplied by Dr. Bruce N. Ames, University of California. The test material was usually dissolved in dimethylsulfoxide.

$330 \mathrm{~g}$ of $\mathrm{D}, \mathrm{L}$-tryptophan was heated in a flask over a gas burner and the resulting tar was condensed in a reservoir cooled by ice. About $205 \mathrm{~g}$ of tar was obtained. The tar was extracted from an alkaline aqueous phase with ether, and the ether extract was evaporated and dissolved in ethyl acetate. The ethyl acetate soluble fraction was then subjected to silica gel column chromatography. After washing with ethyl acetate, a fraction showing mutagenic activity as a single peak was obtained with $30 \%$ methanol in ethyl acetate. Harman and norharman, which were the principal basic products of D, L-tryptophan pyrolysate and which were nonmutagenic in our test, were removed by ethyl acetate washing. The mutagenic fractions were pooled and subjected to alumina column chromatography. They were then eluted with $30 \%$ methanol in ethyl acetate. The pooled mutagenic fractions were further separated on a CM-Sephadex C-25 column. Elution was done with the mixture of methanol and $2.0 \mathrm{~N}$ acetic acid $(3: 1, \mathrm{v} / \mathrm{v})$ to yield a single peak with mutagenic activity. Finally, the pooled mutagenic fractions were further separated into two peaks on a Sephadex LH- 20 column using methanol as a solvent. From the fraction with first peak showing a high mutagenic activity, a crystalline material was obtained as acetate salt. The second peak fraction with a high mutagenic activity was further purified by CM-Sephadex chromatography and another crystalline material was obtained.

The specific mutagenic activities of the crude tar, the pooled mutagenic peak fractions from subsequent purification steps, and final crystalline materials are given in Table I. The presence of mutagenic principles other than the two found could be ruled out

Table I. Purification of tryptophan pyrolysate

\begin{tabular}{l|r|c}
\hline & $\begin{array}{c}\text { Weight } \\
\mathrm{mg}\end{array}$ & $\begin{array}{c}\text { Specific activity } \\
\text { revertants } / \mu \mathrm{g}^{\mathrm{a}} \mathrm{y}\end{array}$ \\
\hline $\mathrm{Tar}$ & 205,000 & 22 \\
Basic fraction & 50,000 & 35 \\
$\mathrm{SiO}_{2}$ column & 1,194 & 600 \\
$\mathrm{Al}_{2} \mathrm{O}_{3}$ column & 160 & 2,100 \\
$\mathrm{CM}-S e p h a d e x$ column & 60 & 5,100 \\
Sephadex LH-20 column, Trp-P-1 & 5 & 6,300 \\
CM-Sephadex column, Trp-P-2 & 10 & 14,000 \\
\hline
\end{tabular}

a) Mutagenic activity with TA98 using S-9 Mix 
based on the pattern of monitoring of the mutagenic activity of fractions during various steps of purification.

The molecular weights of two crystalline substances were determined to be 211.1079 and 197.0921 , respectively, by mass spectroscopy, and the chemical formulas assigned were $\mathrm{C}_{13} \mathrm{H}_{13} \mathrm{~N}_{3}$ and $\mathrm{C}_{12} \mathrm{H}_{11} \mathrm{~N}_{3}$, respectively. Their X-ray crystal analyses led us to deduce plausible structures for the two crystalline substances as shown in Fig. 1. These structures were conformed with the NMR and UV absorption data. The two compounds are designated Trp-P-1 and Trp-P-2, respectively, where $\mathrm{P}$ stands for the pyrolysis product. Detailed data will be published in a full paper elsewhere. Metabolic activation is required to exert the mutagenicity of Trp-P-1 and Trp-P-2.

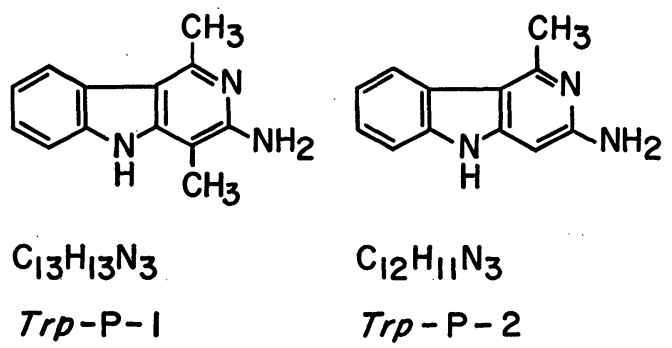

Fig. 1. Plausible structures of mutagenic principles of pyrolytic products of tryptophan.

The tar of $\mathrm{D}$, L-phenylalanine was similarly mutagenic, and an active principle showing mutagenicity was isolated and proved to be 2-amino-5-phenylpyridine, which had previously been isolated as an antifungal substance (Kosuge and Zenda, 1976). Metabolic activation was also required to exert its mutagenicity. The specific mutagenic activity proved to be weaker than that of Trp-P-1 and Trp-P-2 obtained from D, L-tryptophan pyrolysis.

The specific mutagenicity of the two crystalline materials, TrpP-1 and Trp-P-2, was fairly high, and showed a similar degree of the activity as 4-nitroquinoline 1-oxide. Although a strict relation has not yet been established between mutagens and carcinogens, strong mutagenic principles as represented by $N$-methyl- $N^{\prime}$-nitro$N$-nitrosoguanidine, 2-(2-furyl)-3-(5-nitro-2-furyl)acrylamide and aflatoxin $B_{1}$ have been known to be strong carcinogens. Carcinogens that show much less mutagenic activity than Trp-P-1 and Trp-P-2 include many typical carcinogens, such as $N$-2-fluorenylacetamide, $N, N$-dimethyl-4-aminoazobenzene, benzo(a) pyrene and $N$-nitrosodimethylamine. It is, therefore, quite reasonable to expect the car- 
cinogenicity of these crystalline materials and to test their carcinogenic activities in viro. Experiment using crude tar and partially purified fractions including Trp-P-1 and Trp-P-2, have already been started. Their organic syntheses are going on and studies on their effect on chromosomes and mutation using cultured mammalian cells, are now under investigation.

Mass spectrography may be very useful in the quantitative determination of these substances in various cooked foods and smoke condensates. The structures of mutagenic principles from the pyrolysis products of L-glutamic acid, L-serine, L-lysine and L-ornithine will be soon elucidated, too.

\section{References}

Ames, B. N., McCann, J., and Yamasaki, E. (1975) : Mutation Res., 31, 347-364.

Kosuge, T., and Zenda, H. (1976) : Yuki Gosei Kagaku Kyokai Shi, 34, 612-624 (in Japanese).

McCann, J., Choi, E., Yamasaki, E., and Ames, B. N. (1975) : Proc. Natl. Acad. Sci. U. S. A., 72, 5135-5139.

Nagao, M., Honda, M., Seino, Y., Yahagi, T., and Sugimura, T. (1977a) : Cancer Letters, in press.

Nagao, M., Yahagi, T., Seino, Y., Sugimura, T., and Ito, N. (1977b) : Mutation Res., in press.

Sugimura, T., Nagao, M., Kawachi, T., Honda, M., Yahagi, T., Seino, Y., Matsushima, T. Shirai, A., Sawamura, M., Sato, S., Matsumoto, H., and Matsukura, N. (1977) : Origin of Human Cancer, Cold Spring Harbor Laboratory Symposium. Cold Spring Harbor, in press.

Sugimura, T., Sato, S., Nagao, M., Yahagi, T., Matsushima, T., Seino, Y., Takeuchi, M., and Kawachi, T. (1976): Overlapping of Carcinogens and Mutagens. Fundamentals in Cancer Prevention (eds, P. N. Magee, S. Takayama, T. Sugimura, and T. Matsushima), pp. 191-215. University of Tokyo Press, Tokyo.

Yahagi, T., Nagao, M., Seino, Y., Matsushima, T., Sugimura, T., and Okada, M. (1977) : Mutation Res., in press. 